\title{
Microwave-Promoted Synthesis of Sulfonated Metallophthalocyanines and Aggregation in Different Solvents
}

\author{
Zhenhua Cheng, Na Cui, Shengjuan Jiang, Hongxiao Zhang, Lijun Zhu, and Daohong Xia \\ State Key Laboratory of Heavy Oil Processing, College of Chemical Engineering, China University of Petroleum, Qingdao 266580, China \\ Correspondence should be addressed to Daohong Xia; xiadh@upc.edu.cn
}

Received 1 June 2015; Accepted 5 July 2015

Academic Editor: Somchai Thongtem

Copyright ( 2015 Zhenhua Cheng et al. This is an open access article distributed under the Creative Commons Attribution License, which permits unrestricted use, distribution, and reproduction in any medium, provided the original work is properly cited.

\begin{abstract}
Five metallosulfophthalocyanines ( $\mathrm{Fe}, \mathrm{Ni}, \mathrm{Zn}, \mathrm{Co}$, and $\mathrm{Cu}$ ) compounds were synthesized by microwave irradiation. Compared to the conventional method of synthesis in terms of reaction time and yields, the microwave-promoted synthesis is preferred with high product yield and short reaction time. All synthesized products were characterized with MALDI-TOF mass spectrum, Fourier transform infrared spectroscopy (FT-IR), ultraviolet-visible spectroscopy (UV-Vis), and X-ray diffraction (XRD). Aggregation behavior of the five metallosulfophthalocyanines (MSPc) in different solvents was studied by UV-Vis spectroscopy separately in $\mathrm{N}, \mathrm{N}$-dimethyl formamide (DMF) and $\mathrm{NaOH}$ aqueous solution $(5 \% \mathrm{wt})$. A redshift of maximum absorption wavelength and deviations from Lambert-Beer law with increasing the concentration were observed. The dimerization equilibrium constants $(K)$ of the five MSPc were determined, respectively.
\end{abstract}

\section{Introduction}

As new multifunctional materials, metallophthalocyanine compounds have been widely used in the field of catalysis, particularly in light oil sweetening in petroleum refining industry [1]. However, the applications of metallophthalocyanines (MPc) as catalysts are often restricted due to their poor solubility both in common organic solvents and in water. Also, MPc tend to aggregate through coplanar association of the conjugated phthalocyanine $(\mathrm{Pc})$ rings. In that way, the formed dimer and higher mass aggregates may further reduce their solubility in solvents [2-4]. Thus, unsubstituted $\mathrm{MPc}$ can not be directly used as catalyst for the conversion of mercaptan to disulfide during light oil sweetening. The solubility of MPc compounds in alkali solution (or water) can be improved by introducing electron-withdrawing or electron-donating substituents, such as sulfonic acid, carboxylic acid, or amide groups at the periphery and axial positions of the $\mathrm{Pc}$ ring [5-7]. The conventional synthesis of metallosulfophthalocyanines (MSPc) is time-consuming method with low product yields. In addition, the aggregation of MSPc can result in decreased catalytic activity in oil sweetening application. So studies of the synthesis with convenient method and the aggregation of MSPc in different solvents have been of great interest in the field of catalysis.

Khene et al. [8] reported the microwave synthesis of tetrasulfonated tin phthalocyanine. The microwave synthesis is proved to be a simple and fast approach for formation of MPc complexes. Thus, five sulfonated phthalocyanine metal $(\mathrm{Fe}, \mathrm{Co}, \mathrm{Ni}, \mathrm{Cu}$, and $\mathrm{Zn}$ ) compounds were synthesized with the assistance of microwave, and their aggregation behavior was studied.

\section{Materials and Methods}

2.1. Materials and Equipment. All reagents and solvents were AR grade and obtained from the State Chemicals Corp. Synthesis of the five MSPc was performed on a NOVAII microwave reactor with the output power being $500 \mathrm{~W}$ (PreeKem Scientific Instruments Co., Ltd.). FT-IR spectra were recorded on a Nicolet 6700 Fourier transform infrared (Thermo Scientific) spectrophotometer, and electronic spectra were recorded on a Hitachi U-3900H UV-Vis spectrophotometer using $1.0 \mathrm{~cm}$ cuvettes at room temperature. Mass spectra were performed on a BIFLEX III MALDI-TOF mass spectrometer. X-ray diffraction (XRD) was obtained with 
TABLE 1: Reaction temperature for the preparation of sulfonated phthalocyanine metals.

\begin{tabular}{lccc}
\hline \multirow{2}{*}{ Sulfonated phthalocyanine metals } & \multicolumn{3}{c}{ Temperature } \\
& $T_{1} /{ }^{\circ} \mathrm{C}$ & $T_{2} /{ }^{\circ} \mathrm{C}$ & $T_{3} /{ }^{\circ} \mathrm{C}$ \\
\hline CoSPc & 50 & 120 & 150 \\
CuSPc & 50 & 100 & 150 \\
NiSPc & 50 & 100 & 150 \\
FeSPc & 50 & 110 & 140 \\
ZnSPc & 50 & 110 & 140 \\
\hline
\end{tabular}

an X'Pert Pro MPD diffractometer (Panalytical) employing $\mathrm{Cu}-\mathrm{K} \alpha$ radiation (The scanning speed was $8^{\circ}$ per minute and receiving slits were used in conjunction with a $0.3 \mathrm{~mm}$ scatter slit). The morphology of samples was measured with the Hitachi S-4800 cold field emission scanning electron microscope (SEM); resolution was $15 \mathrm{kV}: 1.0 \mathrm{~nm}, 1 \mathrm{kV}: 2.0 \mathrm{~nm}$; accelerating voltage was 0.5 to $30 \mathrm{kV}$; magnification was $30 \times$ 800000; cold field emission electron gun was used.

\subsection{Synthesis}

2.2.1. Cobalt Sulfonated Phthalocyanine (CoSPc). Cobalt sulfonated phthalocyanine was prepared according to the synthetic route (Figure 1) with the microwave irradiation method. Cobalt phthalocyanine $(1.0 \mathrm{~g})$ and $10 \mathrm{~mL}$ of fuming sulfuric acid $(25 \%)$ were added into a quartz tube with a magnetic stirring bar. Then the quartz tube was moved into the MW reactor, and the reaction parameters of time and temperature were set up. The reaction temperature was first raised to $50^{\circ} \mathrm{C}\left(T_{1}\right)$ within $10 \mathrm{~min}$ and maintained for $10 \mathrm{~min}$ and was then raised to $120^{\circ} \mathrm{C}\left(T_{2}\right)$ in $3 \mathrm{~min}$ and maintained for $1 \mathrm{~min}$, followed by $150^{\circ} \mathrm{C}\left(T_{3}\right)$ in $2 \mathrm{~min}$ and kept for $30 \mathrm{~min}$ (shown in Table 1). After reaction, the tube was cooled to room temperature. The reaction mixture was poured into ice water and the precipitate was filtered off, followed by a wash with ice water to neutrality. Then the received crystalline product was dried up under vacuum for 1 day to obtain the pure product. Yield: $0.811 \mathrm{~g}(81.1 \%)$. FT-IR, $v_{\max }\left(\mathrm{cm}^{-1}\right): 3450$ $(\mathrm{O}-\mathrm{H}), 1630(\mathrm{C}=\mathrm{C}), 1520(\mathrm{C}=\mathrm{N}), 1175,1338(\mathrm{O}=\mathrm{S}=\mathrm{O}), 920$ (Co-ligand), 745 (Pc ring), 638 (C-S). UV-Vis (in DMF), $\lambda_{\max }, \mathrm{nm}(\log \varepsilon): 660$ (4.75). MALDI-TOF MS, Calculated: $651.04[\mathrm{M}]$; Found: $652.2[\mathrm{M}+\mathrm{H}]^{+}, 674.1[\mathrm{M}+\mathrm{Na}]^{+}, 690.1$ $[\mathrm{M}+\mathrm{K}]^{+}$.

2.2.2. Sulfonated Phthalocyanine Metals ( $\mathrm{Fe}, \mathrm{Cu}, \mathrm{Ni}$, and $\mathrm{Zn}$ ). The other sulfonated phthalocyanine metals $(\mathrm{Fe}, \mathrm{Ni}, \mathrm{Cu}$, and $\mathrm{Zn}$ ) were all prepared in the same way (as shown in Figure 1). The programmed reaction temperatures of the synthesis of sulfonated phthalocyanine metals were all listed in Table 1.

FeSPc, Yield: $0.657 \mathrm{~g}(65.7 \%)$. FT-IR, $v_{\max }\left(\mathrm{cm}^{-1}\right): 3066$ $(\mathrm{Ar}-\mathrm{H}), 1608(\mathrm{C}=\mathrm{C}), 1150,1180,1315,1385(\mathrm{O}=\mathrm{S}=\mathrm{O}), 1482$ $(\mathrm{C}=\mathrm{N}), 740$ (Pc ring), 650 (C-S). UV-Vis (DMF), $\lambda_{\max }, \mathrm{nm}$ $(\log \varepsilon): 697$ (4.21). MALDI-TOF MS, Calculated: 648.04 [M]; Found: $647.3[\mathrm{M}]^{+}$.

CuSPc, Yield: $0.764 \mathrm{~g}(76.4 \%)$. FT-IR, $v_{\max }\left(\mathrm{cm}^{-1}\right): 3440$ $(\mathrm{O}-\mathrm{H}), 1620(\mathrm{C}=\mathrm{C}), 1505(\mathrm{C}=\mathrm{N}), 1170,1340(\mathrm{O}=\mathrm{S}=\mathrm{O}), 905$
(Cu-ligand), 738 (Pc ring), 638 (C-S). UV-Vis (DMF), $\lambda_{\max }$, $\mathrm{nm}(\log \varepsilon): 671$ (5.10). MALDI-TOF MS, Calculated: 655.04 [M]; Found: $655.9[\mathrm{M}+\mathrm{H}]^{+}, 677.9[\mathrm{M}+\mathrm{Na}]^{+}$.

NiSPc, Yield: $0.743 \mathrm{~g}(74.3 \%)$. FT-IR, $v_{\max }\left(\mathrm{cm}^{-1}\right): 3440$ $(\mathrm{O}-\mathrm{H}), 1630(\mathrm{C}=\mathrm{C}), 1470(\mathrm{C}=\mathrm{N}), 1178,1340(\mathrm{O}=\mathrm{S}=\mathrm{O}), 920$ (Ni-ligand), 738 (Pc ring), 640 (C-S). UV-Vis (DMF), $\lambda_{\max }$, nm $(\log \varepsilon): 666$ (4.97). MALDI-TOF MS, Calculated: 650.04 [M]; Found: $649.9[\mathrm{M}]^{+}, 672.9[\mathrm{M}+\mathrm{Na}]^{+}$.

ZnSPc, Yield: $0.700 \mathrm{~g}(70.0 \%)$. FT-IR, $v_{\max }\left(\mathrm{cm}^{-1}\right): 3060$ $v($ Ar-H), $1610(\mathrm{C}=\mathrm{C}), 1470(\mathrm{C}=\mathrm{N}), 1180,1310,1380(\mathrm{O}=\mathrm{S}=\mathrm{O})$, 720 (Pc ring), 658 (C-S). UV-Vis (DMF), $\lambda_{\max }, \mathrm{nm}(\log \varepsilon)$ : 672 (4.73). MALDI-TOF MS, Calculated: 656.04 [M]; Found: $679.9[\mathrm{M}+\mathrm{Na}]^{+}$.

2.3. Dimerization Constant Measurements. Aggregation of MSPc would lead to deviation from Lambert-Beer law using UV-Vis spectroscopy; thus dimerization can be determined by measuring the relations of absorbance and concentration of MSPc in different solvents. The measurements were accomplished with reference to the method reported in previous work [9]. All of the sample solutions were freshly made and the absorbance was measured on the same day.

\section{Results and Discussion}

3.1. Synthesis and Characterization. The sulfonated metallophthalocyanines were synthesized by microwave heating with shorter reaction time which could help to control the number of sulfonic groups in the Pc ring. However, the conventional synthesis of MSPc not only employed a longer reaction time (as long as $6 \mathrm{~h}$ ) but also employed more dangerous feed (such as chlorosulfonic acid), leading to the uncertainty of the numbers of the sulfonic groups in the Pc ring and the impurity of the product $[10,11]$. The products synthesized using microwave mainly included one sulfonic group in the Pc ring, which were proved by MS and XRD measurements. The improved methods including temperature programmed and shorter reaction time were responsible for the pure product with a higher yield. The characterization of the synthesized products involved a combination of spectroscopic measurement (UV-Vis, FT-IR, $\mathrm{XRD}$, and mass spectroscopy) and morphology analysis.

By checking FT-IR spectra, a strong absorption peak appears near $3400 \mathrm{~cm}^{-1}$, which is due to the $\mathrm{O}-\mathrm{H}$ stretching vibration of sulfonic group. Conjugated $\mathrm{C}=\mathrm{C}$ and $\mathrm{C}=\mathrm{N}$ bonds have relatively similar bond lengths, so the stretching vibration of $\mathrm{C}=\mathrm{C}$ and $\mathrm{C}=\mathrm{N}$ appears at around $1600 \mathrm{~cm}^{-1}$ and $1500 \mathrm{~cm}^{-1}$ [12-14]. In addition, indicative peaks appearing in the range of $1190-1120 \mathrm{~cm}^{-1}, 1390-1290 \mathrm{~cm}^{-1}$ were assigned to $\mathrm{O}=\mathrm{S}=\mathrm{O}$ stretching vibration, and $710-745 \mathrm{~cm}^{-1}$ to the vibration of Pc rings. In the mass spectra of the five compounds, the presence of the characteristic molecular ion peaks at $\mathrm{m} / \mathrm{z}$ $655.9[\mathrm{M}+\mathrm{H}]^{+}, 677.9[\mathrm{M}+\mathrm{Na}]^{+}$for $\mathrm{CuSPc}$ and $649.9[\mathrm{M}]^{+}$, $672.9[\mathrm{M}+\mathrm{Na}]^{+}$for NiSPc confirmed the target structures. And molecular ion peaks are observed at $m / z 652.2[\mathrm{M}+\mathrm{H}]^{+}$ for CoSPc, $647.3[\mathrm{M}]^{+}$for the sodium salt of FeSPc, and 679.9 $[\mathrm{M}+\mathrm{Na}]^{+}$for the sodium salt of ZnSPc. 


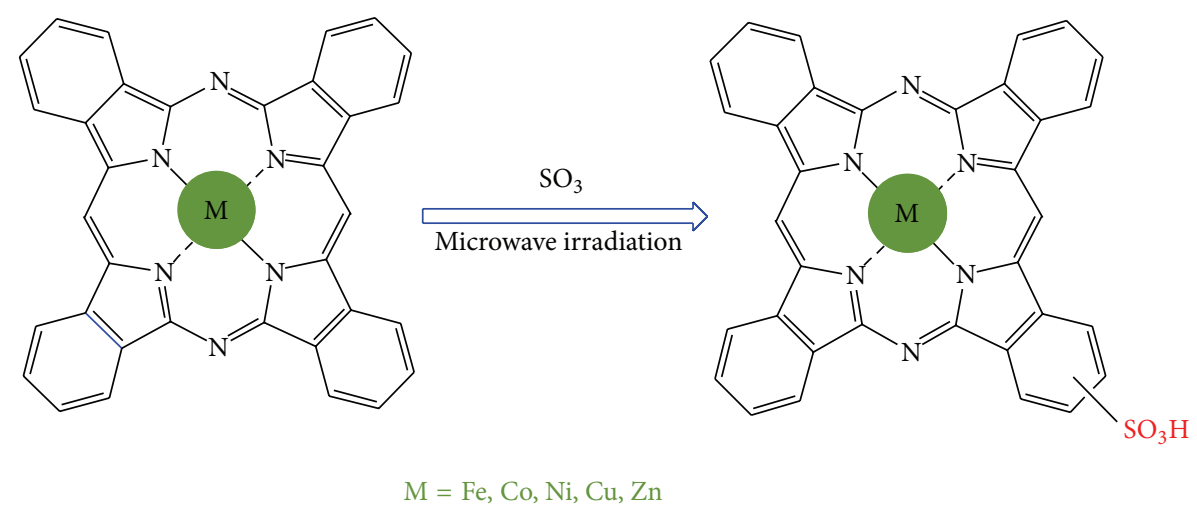

FIGURE 1: Synthetic route of sulfonated phthalocyanine metals via microwave-promoted procedure.
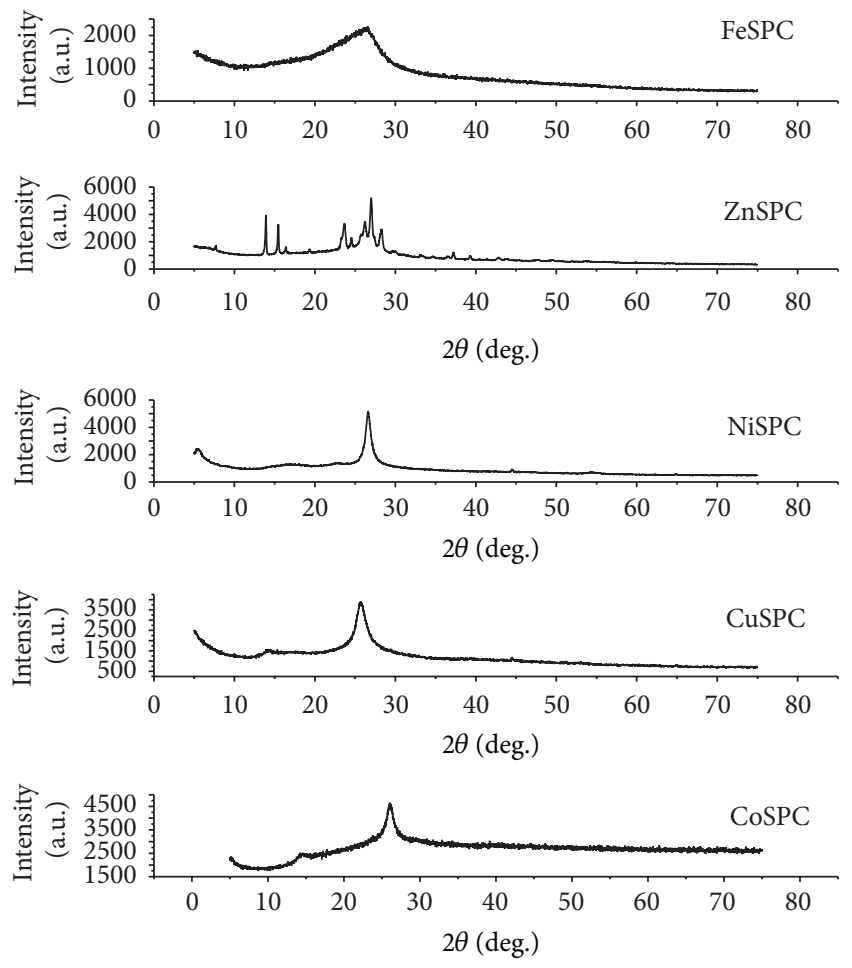

FIGURE 2: XRD patterns of the sulfonated phthalocyanine metals.

Figure 2 shows the XRD patterns of the sulfonated phthalocyanine metals. Apart from the XRD spectrum of $\mathrm{ZnSPc}$ which has mixed peaks, the spectra of other four compounds present intense singlet form. The difference can be explained by the crystallinity of the sulfonated phthalocyanine metals. The spikes of the XRD spectra for ZnSPc indicate its high crystallinity, while the crystallinities of the other four sulfonated phthalocyanine metals are relatively low. The XRD spectra of the five sulfonated phthalocyanine metals suggest that the products synthesized were pure sulfonated phthalocyanine metals with one sulfonic group.

In the SEM micrographs of the five compounds (Figure 3), the absence of flocculent and amorphous structure indicates that the synthesized sulfonated phthalocyanine metals had high crystallinity, which is consistent with the results obtained from XRD patterns. Crystal morphology analysis from Figure 3 shows that CoSPc and CuSPc particles have similar size range, and FeSPc has smaller size crystal. In NiSPc appears some crystal grain accumulation, and ZnSPc exhibits different rod-like morphology with varying lengths and thickness. The elongated rod-like structure was attributed to the $\pi-\pi$ interaction between molecules, leading to the formation of stacked layers of Pc plane.

3.2. Electronic Absorption Spectra. In general, the typical electronic spectra of sulfonated phthalocyanine metals exhibit two strong absorption regions: $B$ band $(300-400 \mathrm{~nm})$ in the ultraviolet region and Q band $(600-700 \mathrm{~nm})$ in the visible region, both of which are correlated with the $\pi-\pi^{*}$ transitions $[15,16]$. The characteristic Q band of sulfonated metallophthalocyanines was observed as an intense singlet in the visible region of the electronic spectrum. The UV-Vis spectra of the studied sulfonated phthalocyanine metals in DMF were shown in Figure 4, and their characteristic bands were listed in Table 2. Q bands $\left(\lambda_{\max }\right)$ of the five compounds (Co, Ni, Cu, Zn, and Fe) at 660, 666, 671, 672, and $697 \mathrm{~nm}$ are in singlet forms with shoulders at 599, 600,604, and $606 \mathrm{~nm}$, respectively, except for FeSPc. Also, CuSPc has the highest extinction coefficient $(\log \varepsilon)$ at $\mathrm{Q}$ band region. Comparing to the absorption band of CoSPc, significant redshifts in $\mathrm{Q}$ band were observed for NiSPc, $\mathrm{CuSP}, \mathrm{ZnSPc}$, and FeSPc. The central metals significantly affect the $\mathrm{Q}$ band of the sulfonated phthalocyanine metals when the phthalocyanines are bonding with transition metals. The redshift increases as the increasing of atomic number of the central metal. In this study, the redshift increases in the order: $\mathrm{Co}, \mathrm{Ni}, \mathrm{Cu}$, and $\mathrm{Zn}$, except for the aggregated FeSPc.

3.3. Aggregation Equilibrium Constant. Many literatures have reported that phthalocyanines tend to aggregate, especially in polar solvents [17-19]. In this study, the aggregation equilibrium constants of CoSPc and the other four MSPc in $\mathrm{DMF}$ and in $5 \% \mathrm{NaOH}$ solution with the concentration range from $6.00 \times 10^{-6}$ to $3.00 \times 10^{-5} \mathrm{M}$ were investigated, respectively. 


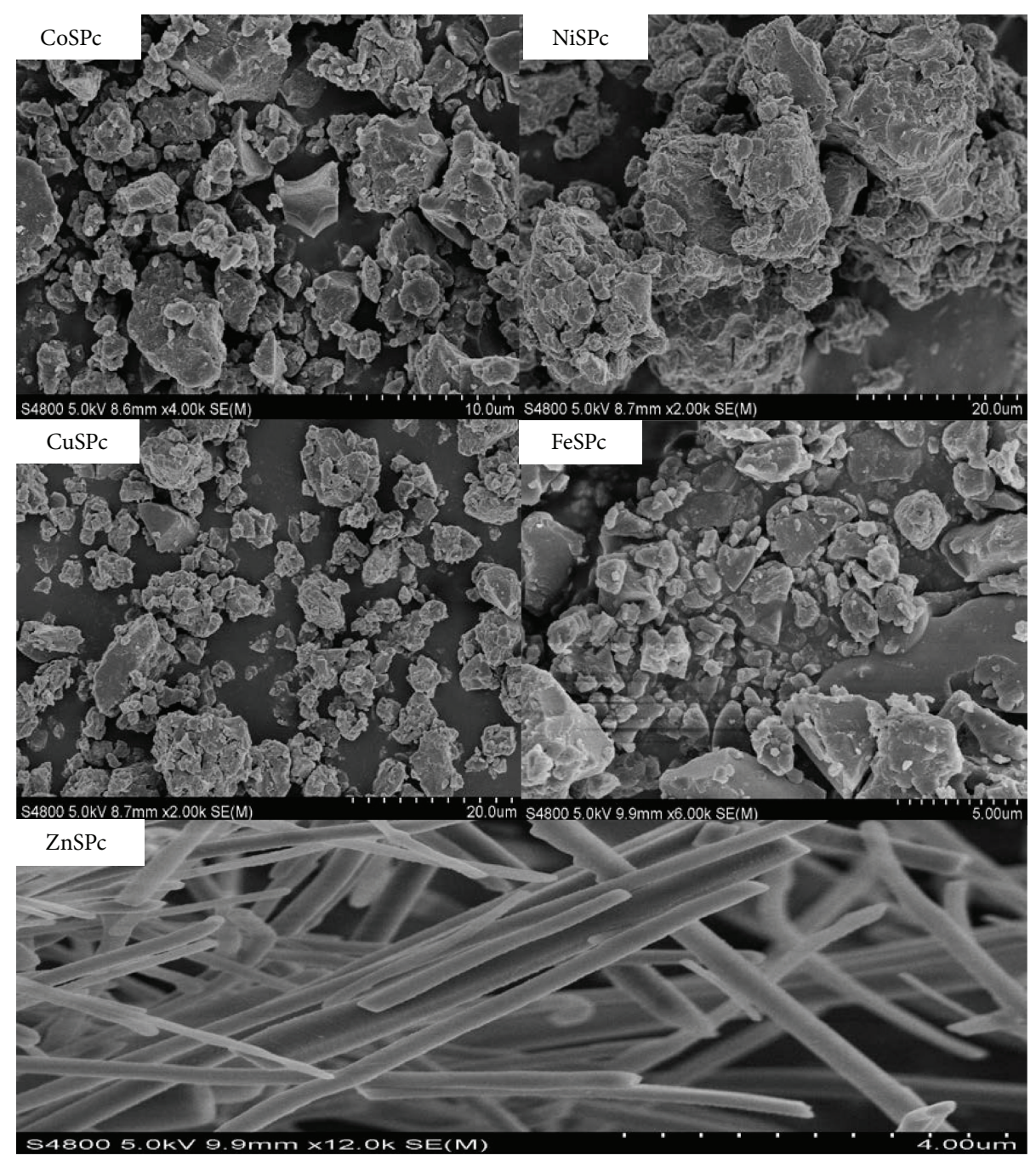

FIGURE 3: The electron micrographs of the five sulfonated phthalocyanine metals.

TABLE 2: Absorption spectral data for sulfonated phthalocyanine metals in DMF $\left(c=2 \times 10^{-5} \mathrm{M}\right)$.

\begin{tabular}{lcc}
\hline Compound & Q band $\lambda_{\max },(\mathrm{nm})$ & $\log \varepsilon$ \\
\hline CoSPc & 660 & 4.75 \\
CuSPc & 671 & 5.10 \\
FeSPc & 697 & 3.76 \\
ZnSPc & 672 & 4.73 \\
NiSPc & 666 & 4.97 \\
\hline
\end{tabular}

Figures 5 and 6 are the absorbance of cobalt sulfonated phthalocyanine in $\mathrm{DMF}$ and in $5 \% \mathrm{NaOH}$ solution at different wavelengths separately. The inset is the relationship between the absorbance at maximum absorption wavelength and the concentration of CoSPc. It can be seen from the inset in Figures 5 and 6 that, at lower concentration of CoSPc, the Lambert-Beer law was obeyed in DMF in the concentration range from $6 \times 10^{-6}$ to $1.4 \times 10^{-5} \mathrm{M}$ and in $5 \% \mathrm{NaOH}$ solution ranging from $2 \times 10^{-6}$ to $1.5 \times 10^{-5} \mathrm{M}$. This finding indicated that $\operatorname{CoSPc}$ was mainly monomer with no dimerization in the solution of concentration below $1.4 \times 10^{-5} \mathrm{M}$ in DMF and concentration below $1.5 \times 10^{-5} \mathrm{M}$ in $5 \% \mathrm{NaOH}$ solution. At higher concentration of CoSPc in solvents, LambertBeer law was not obeyed, and redshifts of the $Q$ band absorption were observed with increasing the concentration of CoSPc both in DMF and in sodium hydroxide solution, which was considered to be caused by dimerization of metal phthalocyanine [20]. Also, the dimerization became stronger with increase in the concentration of CoSPc in the solvents [9].

The dimerization equilibrium constant $K$ could be calculated for sulfonated phthalocyanine metals according to literature [9] by plotting the $\varepsilon \sim \varepsilon^{2}[\mathrm{M}]_{0}$ curves $(\varepsilon$ represents the absorption coefficient and $[\mathrm{M}]_{0}$ represents the initial concentration of $\mathrm{MSPc}$ ), and the results were listed in Table 3. It can be seen from Table 3 that the aggregation equilibrium constant $K$ of $\mathrm{CuSPc}\left(K_{\mathrm{CuSPc}}\right)$ was significantly greater than that of FeSPc $\left(K_{\mathrm{FeSPc}}\right)$ in DMF, while $K_{\mathrm{FeSPc}}$ was slightly higher than $K_{\mathrm{CuSPc}}$ in $5 \%$ sodium hydroxide solution. The aggregation equilibrium constants of NiSPc and $\operatorname{CoSPc}$ were quantitatively similar both in DMF and in 


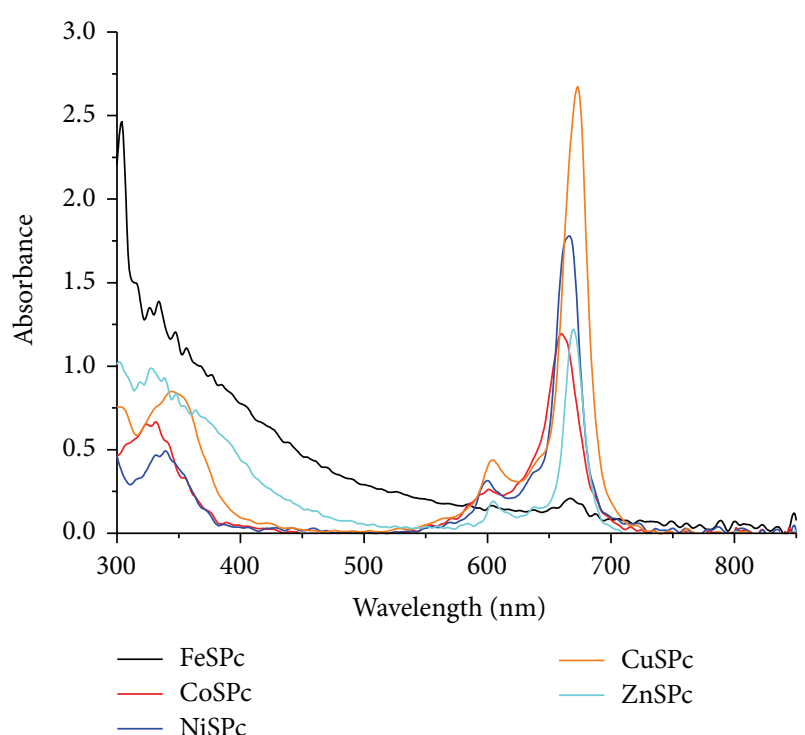

FIGURE 4: Absorption spectra of sulfonated phthalocyanine metals in $\operatorname{DMF}\left(2 \times 10^{-5} \mathrm{M}\right)$

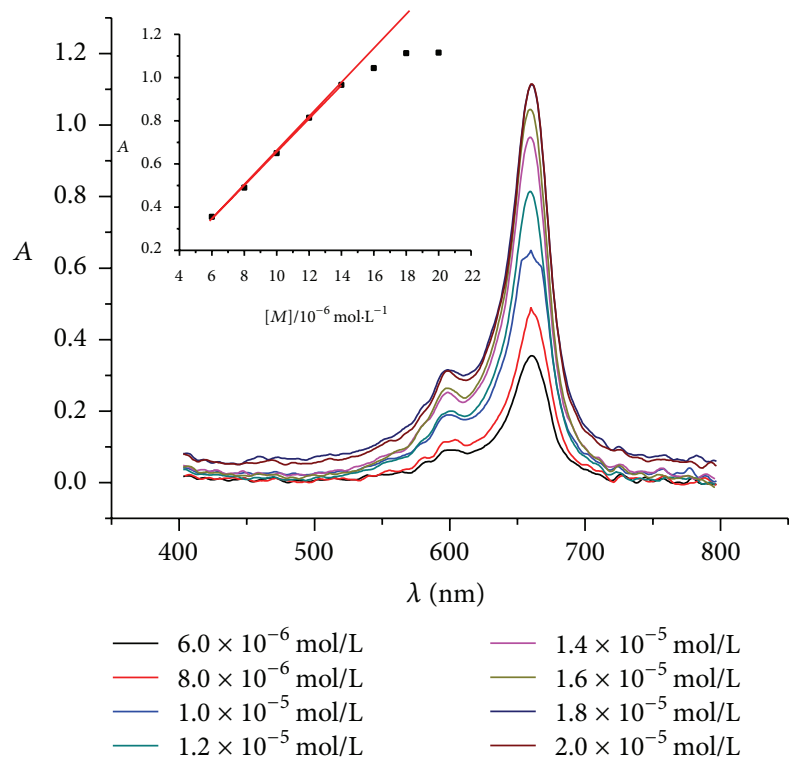

FIGURE 5: Absorbance of cobalt sulfonated phthalocyanine in DMF. (The inset is the relationship between the absorbance at maximum absorption wavelength and the concentration.)

5\% sodium hydroxide solution. Generally, the aggregation equilibrium constants of sulfonated phthalocyanine metals in DMF were greater than those in $5 \%$ sodium hydroxide solution except FeSPc. The effects of aprotic solvents on the aggregation varied with the central metals, and the relations between aggregation and the polarity of aprotic solvents were not obvious in this study. However, it was reported that in polar protic solvent [21], such as in $\mathrm{H}_{2} \mathrm{O}, \mathrm{CH}_{3} \mathrm{OH}$, the aggregation tendency of sulfonated phthalocyanine metals becomes stronger with increasing the polarity of solvents.

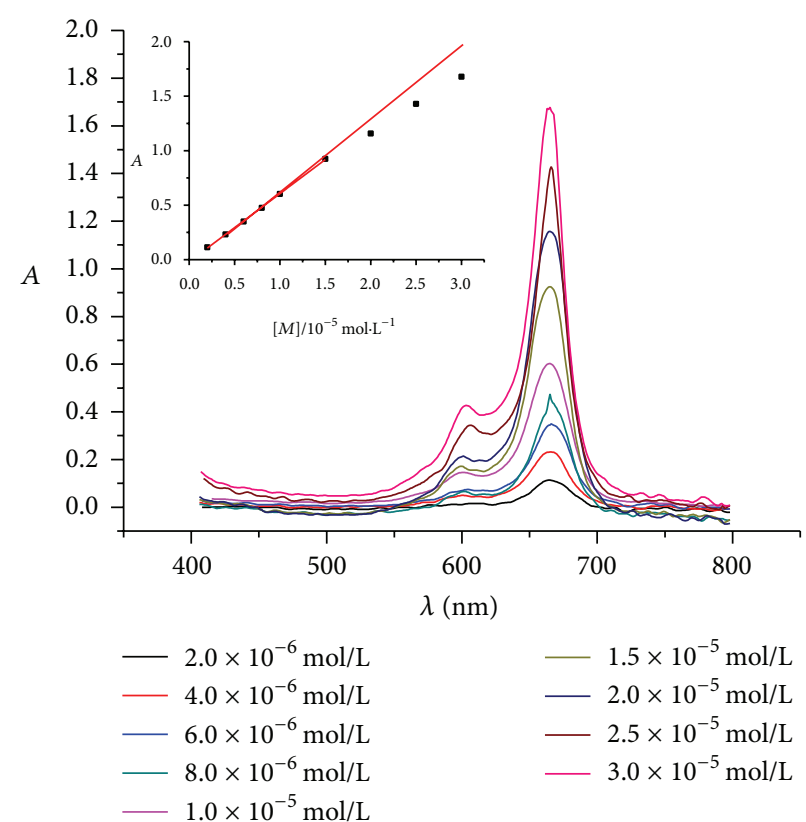

FIGURE 6: Absorbance of cobalt sulfonated phthalocyanine in 5\% sodium hydroxide solution. (The inset is the relationship between the absorbance at maximum absorption wavelength and the concentration.)

TABLE 3: Aggregation equilibrium constant $K$ of the five sulfonated phthalocyanine metals $\left(30^{\circ} \mathrm{C}\right)$.

\begin{tabular}{lcc}
\hline $\begin{array}{l}\text { Sulfonated } \\
\text { phthalocyanine metals }\end{array}$ & $\begin{array}{c}K \text { in solution of } \\
\mathrm{DMF} / \mathrm{mol}^{-1} \cdot \mathrm{L}\end{array}$ & $\begin{array}{c}K \text { in solution of } 5 \% \\
\text { sodium } \\
\text { hydroxide } / \mathrm{mol}^{-1} \cdot \mathrm{L}\end{array}$ \\
\hline CoSPc & $6.16 \times 10^{3}$ & $2.62 \times 10^{3}$ \\
ZnSPc & $4.72 \times 10^{3}$ & $1.79 \times 10^{3}$ \\
CuSPc & $1.50 \times 10^{4}$ & $2.79 \times 10^{2}$ \\
FeSPc & $6.45 \times 10^{2}$ & $1.51 \times 10^{3}$ \\
NiSPc & $7.10 \times 10^{3}$ & $2.39 \times 10^{3}$ \\
\hline
\end{tabular}

\section{Conclusions}

Microwave-promoted synthesis of five sulfonated metallophthalocyanines had been accomplished successfully with short reaction time and one sulfonic group in the Pc ring. It was found that $\mathrm{CoSPc}$ was mainly monomer with no dimerization in the solution of concentration below $1.4 \times 10^{-5} \mathrm{M}$ in DMF and concentration below $1.5 \times 10^{-5} \mathrm{M}$ in $5 \% \mathrm{NaOH}$ solution. At higher concentration of CoSPc in solvents, the disobeyed Lambert-Beer law and redshifts of the Q band absorption were observed. The aggregation equilibrium constants of the five synthesized sulfonated metallophthalocyanines were measured in $\mathrm{DMF}$ and in $5 \% \mathrm{NaOH}$ solution. The aggregation equilibrium constants of sulfonated phthalocyanine metals in DMF were greater than those in $5 \%$ sodium hydroxide solution except FeSPc. 


\section{Conflict of Interests}

The authors declare that there is no conflict of interests regarding the publication of this paper.

\section{Acknowledgments}

The authors thank the financial support from the National Natural Science Foundation of China (Grant no. 21376265) and the Fundamental Research Funds for the Central Universities (15CX02029A).

\section{References}

[1] D. Czakis-Sulikowska, J. Radwańnska-Doczekalska, M. Markiewicz, and M. Pietrzak, "Thermal characterization of new complexes of $\mathrm{Zn}(\mathrm{II})$ and $\mathrm{Cd}(\mathrm{II})$ with some bipyridine isomers and propionates," Journal of Thermal Analysis and Calorimetry, vol. 93, no. 3, pp. 789-794, 2008.

[2] M. García-Iglesias, J.-H. Yum, R. Humphry-Baker et al., "Effect of anchoring groups in zinc phthalocyanine on the dyesensitized solar cell performance and stability," Chemical Science, vol. 2, no. 6, pp. 1145-1150, 2011.

[3] Z. Gasyna, N. Kobayashi, and M. J. Stillman, "Optical absorption and magnetic circular dichroism studies of hydrogen, copper(II), zinc(II), nickel(II), and cobalt(II) crown ethersubstituted monomeric and dimeric phthalocyanines," Journal of the Chemical Society, Dalton Transactions, vol. 12, pp. 2397$2405,1989$.

[4] D. D. Dominguez, A. W. Snow, J. S. Shirk, and R. G. S. Pong, "Polyethyleneoxide-capped phthalocyanines: limiting phthalocyanine aggregation to dimer formation," Journal of Porphyrins and Phthalocyanines, vol. 5, no. 7, pp. 582-592, 2001.

[5] İ. Özceşmeci, A. Gelir, and A. Gül, "Synthesis and photophysical properties phthalocyanine-pyrene dyads," Dyes and Pigments, vol. 92, no. 3, pp. 954-960, 2012.

[6] M. Özçeşmeci, İ. Sorar, and E. Hamuryudan, "Synthesis, optical and structural studies of tetrakis $\left[4-\left(2^{\prime}, 3^{\prime}, 4^{\prime}, 5^{\prime}, 6^{\prime}\right.\right.$-pentafluorobenzyloxy)benzyloxy]-substituted metallo-phthalocyanines," Synthetic Metals, vol. 162, no. 1-2, pp. 154-161, 2012.

[7] K. Palewska, J. Sworakowski, J. Lipiński, and S. Nešprek, "Effect of electric permittivity of the solvent on aggregation process of the water-soluble sulfonated metal phthalocyanines," Journal of Photochemistry \& Photobiology A: Chemistry, vol. 223, no. 2-3, pp. 149-156, 2011.

[8] S. Khene, A. Ogunsipe, E. Antunes, and T. Nyokong, "Microwave synthesis and photophysics of new tetrasulfonated tin(II) macrocycles," Journal of Porphyrins and Phthalocyanines, vol. 11, no. 2, pp. 109-117, 2007.

[9] J. B. Liu, Y. Zhao, F. S. Zhang et al., "Dimerization of metalfree sulfonated phthalocyanines in aqueous methanol solution," Acta Physico-Chimica Sinica, vol. 12, no. 2, pp. 163-168, 1996.

[10] B. N. Achar, G. M. Fohlen, J. A. Parker, and J. Keshavayya, "Synthesis and structural studies of metal(II) 4,9,16,23phthalocyanine tetraamines," Polyhedron, vol. 6, no. 6, pp. 1463-1467, 1987.

[11] Z. S. Wang and Y. M. Xu, "Study on synthesis and dye wastewater photo-catalytic degradation of irontetrasulfophthalocyanine," Shanghai Environmental Sciences, vol. 20, no. 10, pp. 480-481, 2001.
[12] Z.-P. Guo, M.-G. Wu, and M.-X. Zhan, "Syntheses and properties for strontiumphthalocyanine and its sulfonated derivative," Chemical Journal of Chinese Universities, vol. 20, no. 3, pp. 350352, 1999.

[13] T. Kobayashi, F. Kurokawa, N. Uyeda, and E. Suito, "The metal-ligand vibrations in the infrared spectra of various metal phthalocyanines," Spectrochimica Acta-Part A: Molecular Spectroscopy, vol. 26, no. 6, pp. 1305-1311, 1970.

[14] A. K. Burat, A. Koca, J. P. Lewtak, and D. T. Gryko, "Preparation, electrochemistry and optical properties of unsymmetrical phthalocyanines bearing morpholine and tert-butylphenoxy substituents," Synthetic Metals, vol. 161, no. 15-16, pp. 1537-1545, 2011.

[15] T. Nyokong, "Desired properties of new phthalocyanines for photodynamic therapy," Pure and Applied Chemistry, vol. 83, no. 9, pp. 1763-1779, 2011.

[16] T. T. Tasso, T. Furuyama, and N. Kobayashi, "Absorption and electrochemical properties of cobalt and iron phthalocyanines and their quaternized derivatives: aggregation equilibrium and oxygen reduction electrocatalysis," Inorganic Chemistry, vol. 52, no. 16, pp. 9206-9215, 2013.

[17] S. M. Arabei, D. V. Novik, T. A. Pavich, and K. N. Solov'ev, "Aggregation and spectral properties of $\mathrm{Mg}(\mathrm{II})$ tetracarboxyphthalocyanine in aqueous solutions and solid xerogels," Journal of Applied Spectroscopy, vol. 74, no. 2, pp. 237-244, 2007.

[18] M. Idowu and T. Nyokong, "Synthesis, photophysics and photochemistry of tin(IV) phthalocyanine derivatives," Journal of Photochemistry and Photobiology A: Chemistry, vol. 199, no. 2-3, pp. 282-290, 2008.

[19] K. Nawalany, A. Rusin, M. Kepczyński et al., "Comparison of photodynamic efficacy of tetraarylporphyrin pegylated or encapsulated in liposomes: in vitro studies," Journal of Photochemistry \& Photobiology B: Biology, vol. 97, no. 1, pp. 8-17, 2009.

[20] J. P. Zelina, C. K. Njue, J. F. Rusling, G. N. Kamau, M. Masila, and J. Kibugu, "Influence of surfactant-based microheterogeneous fluids on aggregation of copper phthalocyanine tetrasulfonate," Journal of Porphyrins \& Phthalocyanines, vol. 3, no. 3, pp. 188195, 1999.

[21] Y. C. Yang, J. R. Ward, and R. P. Seiders, "Dimerization of cobalt(II) tetrasulfonated phthalocyanine in water and aqueous alcoholic solutions," Inorganic Chemistry, vol. 24, no. 12, pp. 1765-1769, 1985. 

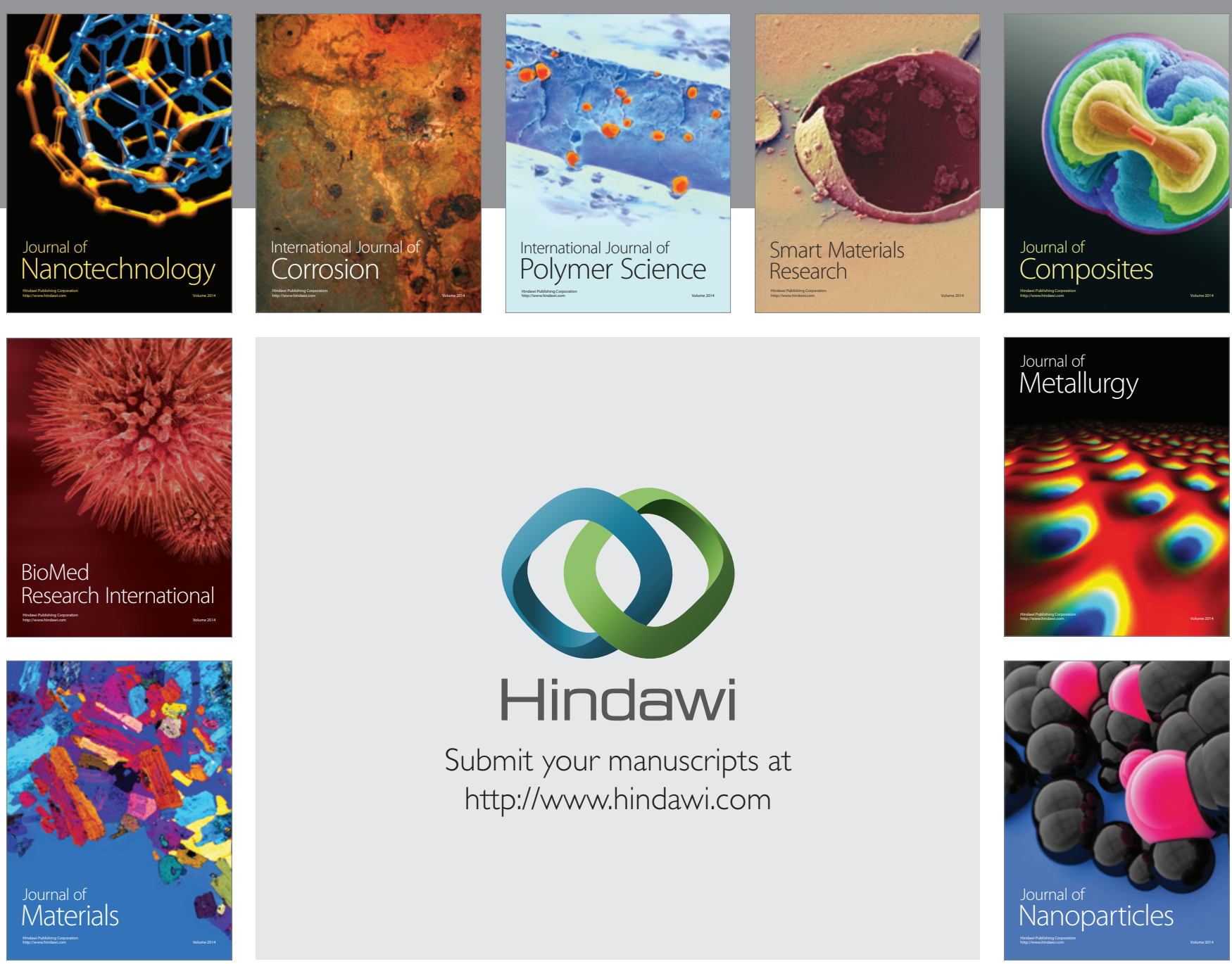

Submit your manuscripts at http://www.hindawi.com
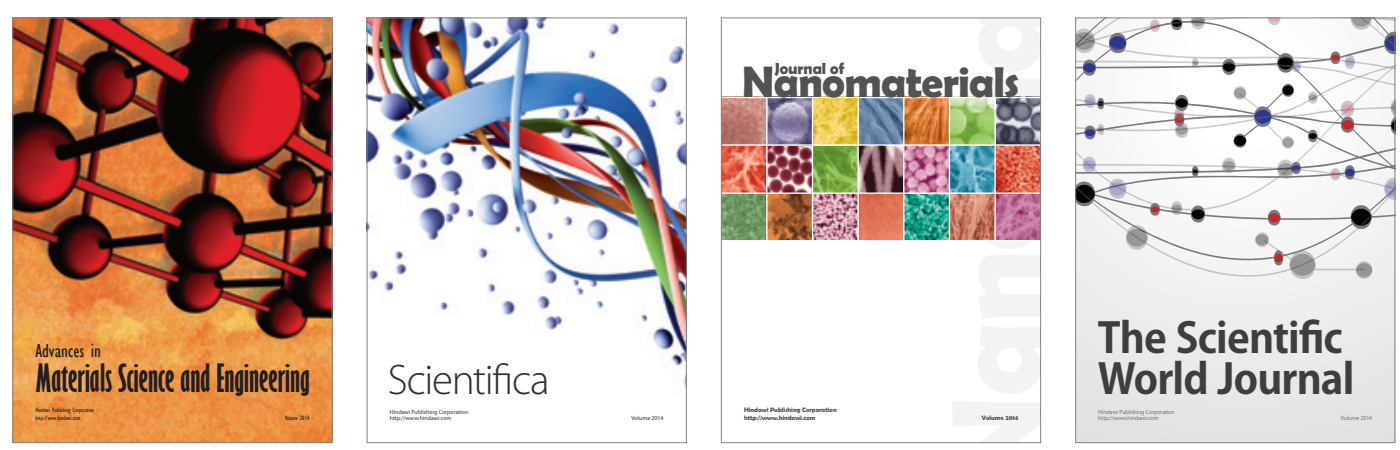

\section{The Scientific World Journal}
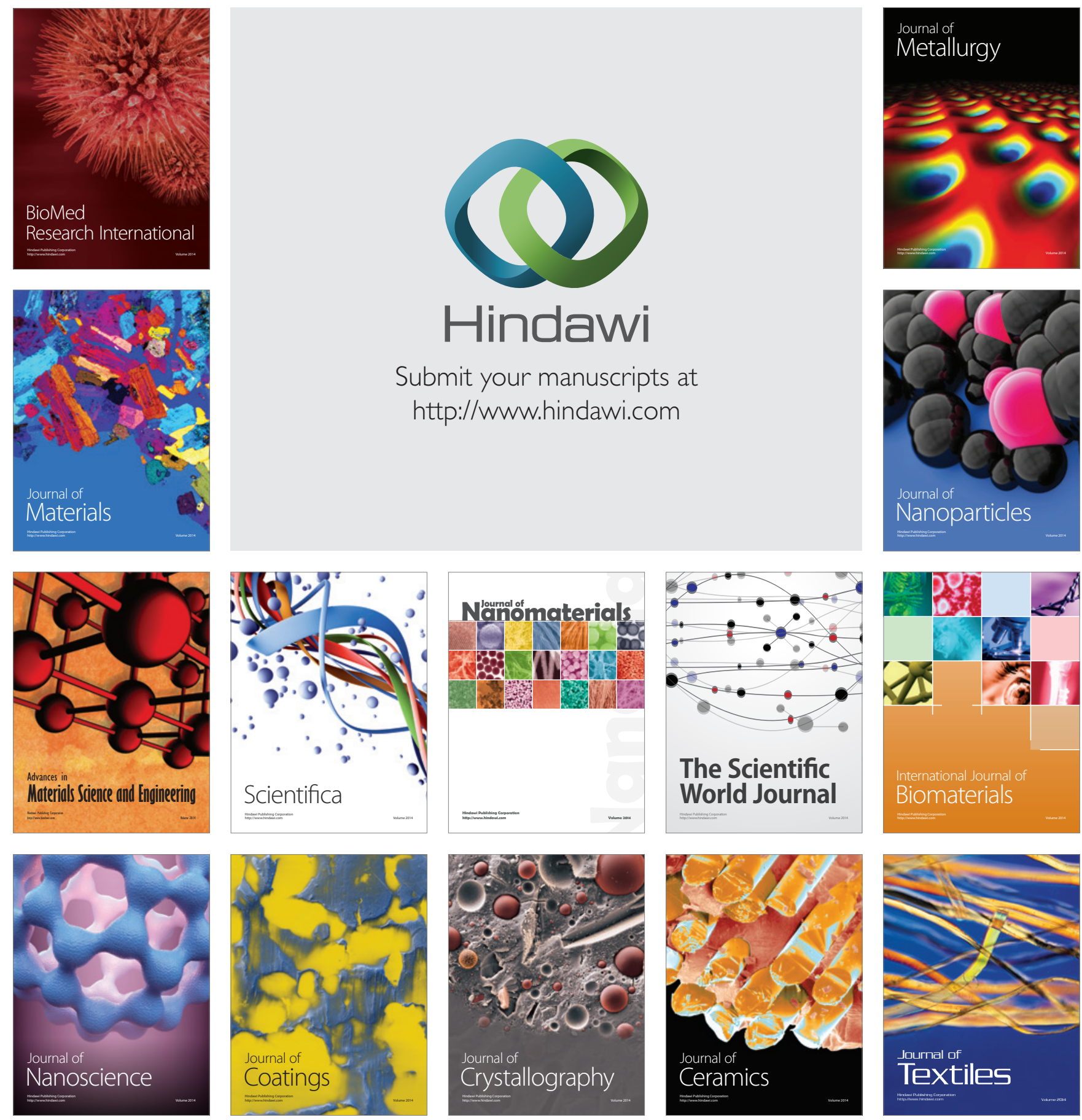